\title{
A Antropologia Psicanalítica: uma chave para pensar o contemporâneo. Entrevista com Paul-Laurent Assoun
}

Psychoanalytical Anthropology is key to think about the contemporariness. Interview with Paul-Laurent Assoun

CL: Paul-Laurent, o que quer dizer antropologia psicanalítica? $O$ que essa noção recobre?

PLA: Bom. Primeiro, a denominação antropologia psicanalítica não está em Freud. Na realidade, a antropologia psicanalítica é o outro nome da própria psicanálise como teoria e clínica do coletivo. Assim, há uma espécie de aspecto redundante na noção de antropologia psicanalítica quase pleonástica, já que a psicanálise é, ipso facto, uma teoria do coletivo.

Esta é uma maneira bastante radical de colocar a questão. Há todo um corpus em Freud que testemunha seu interesse pelo coletivo. Quando escrevi o livro Freud e as ciências sociais: psicanálise e teoria da cultura (2012), introduzi um pouco do discurso do método da antropologia psicanalítica, que se tornou a linha de pesquisa que tivemos no CNRS (Centre National de la Recherche Scientifique) e na Universidade

\footnotetext{
*1 Transcrição e tradução de Elise Alves dos Santos e Vivian Ligeiro.

*2 Universidade Paris VII - Diderot (Paris, França).

${ }^{*}$ Universidade Paris VII - Diderot (Paris, França).
} 
de Paris VII. Depois disto, fiquei ainda mais consciente da extrema riqueza e coerência do corpus freudiano sobre o coletivo.

CL: O que justifica a necessidade de introduzir a noção de uma antropologia psicanalítica para pensar o contemporâneo?

PLA: Podemos então partir da ideia... A psicanálise, até certo ponto, perdeu de vista a ambição de Freud de ter como base clínica uma teoria do coletivo. A partir desse ponto de vista, a ideia de uma antropologia psicanalítica é uma insistência. Lacan, na realidade, não gostava dessa expressão; ele, inclusive, afirmou em uma sessão do Seminário De um Outro ao outro (1968-69/2008) que seria um erro, e até mesmo ridículo, atribuir à psicanálise algo como uma Antropologia Psicanalítica.

É necessário fazer, em primeiro lugar, uma leitura histórica dessa expressão e ilustrar com um conteúdo realmente diferente de Georges Devereux, ${ }^{1}$ por exemplo, que não se utiliza da riqueza da teoria freudiana. Esse autor nos propõe coisas que não são sem interesse, mas que não nos reenviam à herança da posição freudiana.

A psicanálise, para Freud, é um método de investigação dos processos inconscientes, ao mesmo tempo que um método de tratamento de distúrbios neuróticos, mas ela é, também, uma concepção genérica que se aplica ao conjunto do campo da ciência dita do homem. É por isso que ela é capaz de estudar o avesso social dos processos inconscientes, de processos psíquicos inconscientes. Isso é muito importante.

Apesar de Freud não colocar jamais o problema epistemológico formalmente, na plataforma epistemológica presente na introdução do texto "Psicologia das massas e análise do eu" (1921/1977c), ele mostra que a psicossociologia é uma entidade efetiva da relação do sujeito com seu inconsciente, e em relação ao Outro. E nesse texto, Freud escreve o "Outro" com maiúscula e, nesse sentido, esta formulação é pré-lacaniana. Isto é muito importante, pois significa que há, ao lado da relação individual ao outro, uma relação permeada pelo coletivo. $\mathrm{O}$ sujeito traz em si o traço do outro e do coletivo. Evidentemente, o que Freud cita, muitas vezes, é a relação com o médico, a relação transferencial em geral, a relação familiar, a relação com os irmãos. E quando Lacan insiste, dizendo que a fala é a fala do Outro, só acentua o que em Freud já estava presente.

${ }^{1}$ Psicanalista e antropólogo franco-americano. 


\section{ENTREVISTA}

Assim, a antropologia psicanalítica é a psicanálise como antropologia, e é uma antropologia freudiana pelo próprio fato de estar diretamente articulada à hipótese do inconsciente. $\mathrm{O}$ pior destino para a psicanálise seria ela se tornar um simples capítulo de um manual, mais um capítulo de um livro de medicina ou, ainda, de um manual das ciências sociais. Deixar isso acontecer seria uma traição a Freud. E é claro que guardar esta ambição requer que a psicanálise aprofunde sua especificidade, ao mesmo tempo que se mantenha numa dinâmica que pode ser chamada interdisciplinar, numa interdisciplinaridade de fato. Existem muitas equipes de pesquisa em psicanálise que se dizem interdisciplinares, mas na realidade são infiéis a essa dimensão proposta por Freud.

CL: Você poderia nos falar um pouco mais dessa perspectiva freudiana presente em seus textos antropológicos?

PLA: Existe na estrutura de "Totem e tabu" (1913[1912-1913]/1977b), que é um texto que não envelheceu, um método que exige que façamos dele um objeto de atualização constante, para verificar se a estrutura dos fenômenos sociais atuais que observamos, mudaram realmente nos últimos tempos. Lacan chama isso de discurso, uma instância do discurso que é social, que rege a relação entre os seres falantes. É por isso que as atuais noções de discurso são noções que vêm, como dizemos, dar razão, interpelar no sentido mais forte, a antropologia psicanalítica. Na realidade, a antropologia psicanalítica é um instrumento de observação em relação a esses discursos que sustentam a ideia de que atualmente existe uma metamorfose, ou uma mutação social. Existe, assim, a vigência de uma ideia que promove a perspectiva do novo, enquanto nós pensamos que a estrutura não mudou. $\mathrm{Na}$ atualidade o que se verifica é o contrário, pois o homem contemporâneo, sob todas as suas características atuais, continua a ser atravessado pelos seus medos infantis, e a realidade fornece um alimento cotidiano para a construção de seus sintomas.

CL: Nós vamos falar desta ideia do novo, ou dos novos sintomas, mas antes você poderia nos falar mais sobre esse método? O que quer dizer a antropologia psicanalítica como método de investigação?

PLA: Então, o método quer dizer o caminho. O método é o que possibilita encontrar um caminho em direção ao objeto. Mas não há metodologismo ${ }^{2}$

${ }^{2}$ Metodologismo é o exagero de teorias sobre o método, resultantes da intersecção do cientificismo positivista com o hegelianismo que levam à predominância do know how sobre o know that. O método, a procura do conhecer o conhecimento, transforma-se numa ideologia. 
em Freud, isto é, no sentido de que ele não tem essa ideia de que devemos passar um tempo esfregando os óculos antes mesmo de usá-los... não. $\mathrm{O}$ método é somente algo que faz parte do próprio movimento da investigação do inconsciente. Esse é um ponto muito importante. É por isso que não temos também um método do tipo experimental. Freud afirma claramente que não temos um método empírico. $\mathrm{O}$ que não impede que engendremos a legitimidade de nossa ciência, de nossa jovem ciência, como dizia ele em 1913, na relação com o sujeito, pois é ele que nos ensina tudo. O sujeito da clínica, quer dizer o sujeito do inconsciente. Então como encontrar a questão do coletivo? Não procuramos o coletivo, pois, de fato, ele faz parte do sujeito.

Vamos fazer um sobrevoo rápido sobre o texto freudiano fundador destas questões. Um texto ao qual atribuo grande importância, que foi escrito antes de "Totem e tabu" e que prepara o terreno para "Totem e tabu". O texto é "Moral sexual civilizada e doença nervosa moderna", de 1908, quando Freud se confronta com as questões da sua época e no qual analisa a atitude da psiquiatria da época, face ao progresso social e ao avanço da depressão. É curioso, de fato, como os homens modernos, fazendo progressos materiais efetivos desenvolvem também, ao mesmo tempo, a tristeza. Os psiquiatras da época diziam que o progresso da ciência sobrecarrega o sujeito de tal forma que ele desenvolveria a depressão.

O que diz Freud? Diz que isto tudo são apenas fatores. E quando falamos de fatores, fazemos a soma de fatores, e não vemos a presença, no fundamento disso tudo, da contradição. A contradição é que é a base da cultura. E a contradição existe, pois a cultura é fundada sob a repressão pulsional. E para Freud não é somente uma simples separação entre satisfação e realidade (ou o real), o que está em jogo; é, essencialmente, um impossível de viver que se liga ao estatuto cultural do sujeito. É esse impossível entre a satisfação pulsional e a realidade que fundamenta o edifício cultural. É pela presença desse impossível que existem consequências clínicas essenciais. É esta contradição que faz com que o neurótico não seja simplesmente alguém que tenha sintomas. Ele é o sintoma vivo daquilo que Freud denominará, vinte anos mais tarde, de mal-estar da cultura. É necessário lembrar aos analistas que quando temos diante de nós um paciente, é também o mal-estar na cultura que se deita no divã. O que quer dizer que compreender o sintoma do neurótico é também articulá-lo com o contexto cultural no qual ele vive, caso contrário, caímos no reducionismo psicopatológico e, a psicanálise, numa lógica normativa. Em outros termos, o neurótico não é um simples doente dos nervos, devido a sua impossibilidade de se confrontar com as exigências de repressão pulsional; ele é, na realidade, 


\section{ENTREVISTA}

um dissidente que revela a verdade da sua cultura. É por isso que ele não pode ser uma mera ilustração do que encontramos na caixa da nosologia psicopatológica, pois o seu sintoma é o evento que denuncia a contradição que funda a sua cultura. Se o neurótico tem sintoma é porque ele é o sintoma da sua cultura. O que ele testemunha é uma harmonia impossível entre pulsão e civilização.

Assim, podemos ver isto de uma maneira muito clara, por exemplo, na situação do sujeito em relação ao trabalho. Neste caso, podemos ver como os discursos sociais se constroem em torno do mal-estar, mas, ao mesmo tempo, ignoram o mal-estar tal qual ele foi elaborado por Freud. O discurso social coloca a questão: Por que os sujeitos estão doentes no trabalho? E este mesmo discurso inventa o burnout, ${ }^{3}$ como forma de explicação. Ou então: o que fazer com o sujeito que está traumatizado? E aí eles inventam a resiliência. $\mathrm{Ou}$, ainda, afirmam que há um mal-estar no sexo, mas, tudo bem... é somente uma questão de gênero. Não é que sejamos misoneístas no sentido de recusar o discurso novo, mas no fundo da questão não é o novo que encontramos. Essa é a falsa novidade. No meu seminário, na Maison Suger de Sciences de l'Homme, em Paris, abordo esta questão do mal-estar na cultura que tampamos atualmente com estes "gadgets" sociais. Portanto, o gadget "Burnout" é um discurso social atual que comporta uma metáfora interessante, quer dizer, a destruição do sujeito pelo fogo. No entanto ele é analisado apenas fenomenologicamente.

CL: Quer dizer então, que a partir da leitura antropológica psicanalítica, a ideia de novos sintomas deve ser repensada, pois as construções sintomáticas podem parecer novas, mas o seu fundamento, quer dizer, a procura da satisfação pulsional e a impossível conciliação com a realidade, não mudou?

PLA: Sim, é necessário saber onde localizar o novo, no texto "A moral sexual civilizada e a doença nervosa moderna", quando, antes de falar da origem mítica, Freud fala da condição moderna. A condição da modernidade é a repressão pulsional, o recalque do sexual. Freud, dá a chave do que Foucault nunca compreendeu.

É a partir disso que ele escreve "Totem e tabu". E somente a partir da "Horda primitiva", combinada com a teoria clínica do neurótico obsessivo, e

${ }^{3}$ Síndrome de Burnout: segundo H. J. Freudenberger, trata-se de um distúrbio psíquico de caráter depressivo, precedido de esgotamento físico e mental intenso, cuja causa está intimamente ligada à vida laboral. 
da fobia infantil, que é possível construir uma narrativa da origem. A aliança social começa com este ato violento dirigido contra o pai, o que colore o laço social de culpabilidade coletiva e produz sintomas individuais.

CL: O que você afirma é importante. Quer dizer que o desejo de morte do pai, desejo que o neurótico vive no fantasma, é aquilo que produz nossos ideais sociais?

PLA: São modos de idealizações reacionais. É por isso que me pareceu tão apaixonante escrever Freud e as ciências sociais já que há uma lógica que faz com que Freud, a partir de 1911-1913 com "Totem e tabu", e nos anos 1920-1921, no texto "Psicologia das massas..." nos diz: o pai foi morto e agora criamos e recriamos ideais. Quer dizer, o pai morto, nós o fazemos reviver em permanência, mas sob um fundo de ambivalência. É isto que nos mostra a explosão do nazismo, por exemplo, esse gozo destrutivo. Ou, ainda, a questão da religião em "O futuro de uma ilusão" (Freud, 1927/1977d) e, é claro, a pequena referência em "O mal-estar na civilização". Esses textos têm uma lógica, pois em cada mudança metapsicológica Freud modifica também sua teoria do coletivo. Podemos dizer de modo argumentativo e didático, que em a "A moral sexual civilizada" é a libido que está em jogo, como em "Totem e tabu", e a introdução do narcisismo é o ideal que está presente na psicologia das massas. E finalmente ele introduz a pulsão de morte no texto "Mal-estar na civilizaçao (1930[1929]/1977e), pois o modelo de 1908 já não era mais suficiente para entender os movimentos contraditórios da civilização. Gostaria de tomar a expressão francesa "Le ver est dans le fruit" [literalmente, o verme está na fruta, a qual aponta para algo que se degrada, sem que nada ou ninguém intervenha]; trata-se do verme da pulsão de morte na cultura. Tornar inteligível essa tese do texto "Mal-estar na civilização" é sublinhar o elemento inconsciente da cultura que pode levar à sublimação ou à destruição.

Freud não é anticulturalista. Ele diz que não temos solução melhor do que a cultura... A cultura é capaz de produzir um mecanismo sublimatório que luta permanentemente contra a tendência à destrutividade. Esse é um ponto absolutamente genial. Isso explica a sublimação que vai além do objetivo sexual, mas, por outro lado, se constrói em um terreno minado. É por isso que a sublimação não é o sublime e não existe nada mais sexual que o trabalho de um pintor, um filósofo, um pesquisador etc.

CL: Sim. Este é um outro ponto essencial. A sublimação reagrupa um destino para o sexual, mas, também, certo destino para a pulsão de morte. 


\section{ENTREVISTA}

PLA: É por isto que a sublimação tem esse lado perigoso. O mal-estar e a sublimação são simplesmente os dois lados, negativo e positivo, da cultura. Estes dois (mal-estar e a sublimação) são dois destinos do trabalho do negativo na cultura. O paradoxo fecundo da sublimação é que ela só obtém sua independência face à objetalidade pulsional esvaziando o Eu, o que ameaça o Eu de se colocar à serviço da pulsão de morte. O trajeto freudiano de "Totem e tabu" até "Mal-estar na civilizaçao" vai do "pai" ao "pior", quer dizer, do pai da origem até o destino do coletivo, no desejo de afrontar a negatividade endógena. Este combate interminável faz do "mal-estar" coletivo, o sintoma incurável onde se alimenta o empreendimento sublimatório da cultura.

\section{CL: E a pulsão de morte...?}

PLA: A referência à pulsão de morte — presente em muitas situações clínicas - é acompanhada de uma análise cada vez mais fina dos efeitos do sentimento de culpa inconsciente, aliado à satisfação pulsional. A primeira renúncia pulsional imposta pelas forças exteriores exige novas renúncias pulsionais. É isto que faz com que o Superego seja guloso, como diz Lacan. A recusa da agressão é interiorizada pelo Superego, que vem a ser cada vez mais cruel a cada nova renúncia pulsional. Se é verdade que o abandono da agressividade cria o sentimento de culpa, é verdade, também, que se produz um acúmulo pulsional e de interdição (cultural) que cria o mal-estar próprio da civilização. Cada vez que o sujeito cede à sua pulsão ele se vê, assim, confrontado com uma exigência cada vez mais severa do Superego, o que constrói uma dialética do ódio e da cultura. Esta é a face dupla da cultura, feita de renúncia e criação.

Não podemos desistir de ler e reler Freud! Não temos apenas uma teoria a mais, onde adicionaríamos esse suplemento de alma ao inconsciente. Estou me referindo ao filósofo Bergson que falou de um suplemento de alma. Existem pessoas que pensam que é suficiente colocar um suplemento de alma inconsciente para entender os fenômenos atuais. É complicado eu sei, porque em algumas ciências, pelo menos na Europa, tudo se tornou cada vez mais e mais empírico.

CL: Você falou anteriormente sobre alguns fenômenos chamados novos sintomas. Podemos voltar a essa questão?

PLA: Sim. O princípio é o seguinte: $O$ social percebe que existe um problema ... Exatamente em vez de chamar um sintoma, ele chama a coisa de um problema (ou transtorno) .... é a palavra utilizada. Enfim, as pessoas têm 
um problema, o problema é nomeado e a solução é tratá-lo politicamente, socialmente. No caso do burnout, vemos efetivamente pacientes que estão esgotados. Burnout é um termo que literalmente significa ter se queimado, um pouco como um edifício que está completamente queimado e ao final só resta a carcaça. Na verdade são sujeitos que se queimam, exaurem no trabalho. Em vez de imaginar o que acontece metapsicologicamente neste caso, interessaria saber o que acontece na realidade inconsciente... Por trás do trabalho, há comumente um movimento libidinal, narcísico, agressivo, que é um coquetel explosivo. Então, quando você vê alguém se queixando no trabalho, a questão deveria estar ligada na problemática paterna para esse sujeito, a constituição do seu superego etc. Por exemplo, um sujeito que consegue ter uma situação profissional muito boa como vai organizar sua relação com a figura de um pai que nunca conseguiu avançar profissionalmente? Como vai lidar com a culpa?

CL: Sim, isso também nos levaria a questionar a questão do assédio, assédio no trabalho e assédio sexual...

PLA: É isso. Na França, por exemplo, de repente, descobre-se que há assédio sexual, e aí o social se precipita. Mas veja, há uma extrema ingenuidade no discurso social... o problema de fato é saber o que ocorre entre um homem e uma mulher. Freud dizia em "O futuro da ilusão" que as relações entre os homens, em suma, nunca são normais, porque são governadas na cultura por uma série de ilusões eróticas. Esse é o estilo de Freud. E isso nunca será claro, nunca ficará claro, ou seja, o que produz a realidade do desejo entre um homem e uma mulher... é essa ambiguidade. No entanto, esta situação atual reabre na verdade a questão: como o perverso tem a habilidade de encurralar uma mulher pelo poder? Muito frequentemente, por exemplo, o perverso faz alusões verbais para lembrar a uma mulher que ela "é uma mulher", de inseri-la na castração, o que para ele próprio é o insuportável. Assim ele consegue mantê-la sob seu poder.

No entanto, no momento em que isso se difunde no discurso social, vamos ouvir: Que horror! Mas o que fazer? Esse é o ponto: O que tiramos disso como consequência ideológica?

CL: Isso quer dizer que o discurso social instituído ignora a dimensão inconsciente. No entanto, o mais problemático é quando a comunidade psicanalítica também ignora essa dimensão sexual inconsciente presente no social.

PLA: Sim. As resistências crônicas contra a psicanálise procedem do fato de que ela chama a atenção da sociedade para esse lado escandaloso da 


\section{ENTREVISTA}

sua fundação, o sexual, do qual a sociedade não quer saber. É por isso que a nossa proposta de reescrever "O mal-estar na cultura" é ambiciosa. É o futuro da psicanálise que está nisso. Quer dizer que não se trata de adaptar a psicanálise ao ambiente atual, mas manter a sua especificidade no debate atual. Há uma linda canção de Georges Brassens (direi entre parênteses), não sei se os brasileiros a conhecem "Le boulevard du temps qui passe" (A avenida do tempo que passa). Ele mostra que as novas gerações que chegam querem sempre mudanças, abraçar uma mulher que os velhos não tocam mais... O que faz com que ele verifique que há sempre o aparecimento de novas ideias etc. À medida que o tempo passa, existe sempre também uma época de crises. É uma linda canção "Nós os vimos, foi ontem / Desciam jovens e orgulhosos / A avenida do tempo que passa". Aqui não há mal-estar na cultura, mas há a ideia de que cada geração que chega quer o que é novo. A psicanálise, por sua vez, pode e deve habitar a subjetividade de sua época, mas sem se desfazer de seus fundamentos.

CL: Sim, o que você diz é que o sexual, fundamento da psicanálise, é crônico e sempre volta. Atualmente ele se apresenta apenas com novos trajes.

PLA: Sim, exatamente, é um efeito de retorno permanente que faz com que o inconsciente não deixe o sujeito. O que é certo é que o futuro da psicanálise está aqui. Freud queria ser otimista, já que pensava que de todo modo a ciência avança e a psicanálise, sendo uma ciência, também. Não podemos mais negar o inconsciente. Lacan é menos claro nisso. Ele pensa que a psicanálise é algo que surgiu em dado momento, que foi espantoso, surpreendente, mas que em certo momento poderá acabar. Não é excluída a hipótese de que ela acabe, ao contrário da religião.

\section{CL: Então, para você a psicanalise é imortal?}

PLA: Ela é imortal. Estou convicto de que ela teve um efeito de verdade, como disse Lacan. E nós podemos imaginar como ela pode se posicionar em relação à humanidade do futuro, por exemplo, no debate sobre o humano "aumentado" (Lindenmeyer, 2017) ou no debate sobre o "trans-humanismo". Isto é extremamente importante, já que temos uma posição extremamente forte nesse debate. ${ }^{4} \mathrm{E}$ cada pesquisador que quiser participar de nossa rede

${ }^{4}$ Referimo-nos ao séminario "Le corps augmenté et ses symptômes" no Instituto de Ciências da Comunicaçao do CNRS. Seminário dirigido por Cristina Lindenmeyer, Jean-Michel Besnier, Paul-Laurent Assoun e Samuel Lepastier. <http://www.iscc.cnrs. fr/spip.php?article2268>. 
será uma boa coisa, pois neste retorno a atualização dos textos antropológicos psicanalíticos serão necessários. É urgente refazer o retorno a Freud no campo do coletivo. É aí que a antropologia psicanalítica, apesar da reserva de Lacan, entende fazer a sua fundação. Tendo uma função crítica e não simplesmente fazendo uma acumulação de objetos de pesquisa. Habitar a condição contemporânea. Esta é a posição do analista e a função da psicanálise na atualidade.

\section{Referências}

Assoun P.-L. Freud e as ciências sociais: psicanálise e teoria da cultura. São Paulo, SP: Loyola, 2012.

Freud, S. (1977a). Moral sexual civilizada e doença nervosa moderna. In Edição Standard Brasileira das Obras Psicológicas Completas de Sigmund Freud. Rio de Janeiro, RJ: Imago. (Trabalho original publicado em 1908).

Freud, S. (1977b). Totem et tabu. In Edição Standard Brasileira das Obras Psicológicas Completas de Sigmund Freud. Rio de Janeiro, RJ: Imago. (Trabalho original publicado em 1913[1912-1913]).

Freud, S. (1977c). Psicologia das massas e análise do eu. In Edição Standard Brasileira das Obras Psicológicas Completas de Sigmund Freud. Rio de Janeiro, RJ: Imago. (Trabalho original publicado em 1921).

Freud, S. (1977d). O futuro de uma ilusão. In Edição Standard Brasileira das Obras Psicológicas Completas de Sigmund Freud. Rio de Janeiro, RJ: Imago. (Trabalho original publicado em 1927).

Freud, S. (1977e]). O mal-estar na civilização. In Edição Standard Brasileira das Obras Psicológicas Completas de Sigmund Freud. Rio de Janeiro, RJ: Imago. (Trabalho original publicado em 1930[1929]).

Lacan, J. (2008). O seminário. Livro 16. De um Outro ao outro. Rio de Janeiro, RJ: Jorge Zahar. (Trabalho original publicado em 1968-69).

Lindenmeyer, C. L'humain et ses prothèses. Savoirs et pratiques du corps transformé. Paris, França: CNRS, 2017.

Citação/Citation: Lindenmeyer, C. (2018, setembro). A Antropologia Psicanalítica: uma chave para pensar o contemporâneo. Entrevista com Paul-Laurent Assoun. Revista Latinoamericana de Psicopatologia Fundamental, 21(3), 431-441. http://dx.doi.org/10.1590/ $1415-4714.2018 \mathrm{v} 21 \mathrm{n} 3 \mathrm{p} 431.2$ 


\section{ENTREVISTA}

Editora da entrevista/Editor: Profa. Dra. Cristina Lindenmeyer

Recebido/Received: 30.5.2018 / 5.30.2018 Aceito/Accepted: 5.6.2018 / 6.5.2018

Copyright: (C) 2009 Associação Universitária de Pesquisa em Psicopatologia Fundamental/ University Association for Research in Fundamental Psychopathology. Este é um artigo de livre acesso, que permite uso irrestrito, distribuição e reprodução em qualquer meio, desde que o autor e a fonte sejam citados / This is an open-access article, which permits unrestricted use, distribution, and reproduction in any medium, provided the original authors and sources are credited.

\section{Paul-Laurent Assoun}

Psicanalista; Professor da Universidade Paris VII Diderot. Foi Director da UFR Sciences Humaines Cliniques de 1997 até 2007. É diretor da coleção "Filosofia hoje" da Editora Presses Universitaires de France (PUF), e diretor da coleção "Psicanálise e práticas sociais" da Editora Anthropos/Economica. Autor de inúmeros livros de psicanálise.

paullaurent.assoun@gmail.com

\section{Cristina Lindenmeyer}

Psicanalista; Professora da Universidade Paris VII Diderot; Diretora de pesquisa do Centre de Recherche Psychanalyse, Medecine et Société (CRPMS). Pesquisadora Associada ao 441 polo de pesquisa «Santé connectée et humain augmenté» do Institut de Sciences de la Communication - Centre National de la Recherche Scientifique (CNRS). Trabalha desde 2006 com Paul-Laurent Assoun, na Universidade Paris VII Diderot. Editora Associada da Revista Latinoamericana de Psicopatologia Fundamental, Seção Entrevistas.

cristina.lindenmeyer@wanadoo.fr

This is an open-access article, which permits unrestricted use, distribution, and reproduction in any medium for non-commercial purposes provided the original authors and sources are credited. 